\title{
Directly Valuing Animal Welfare in (Environmental) Economics*
}

\author{
Alexis Carlier ${ }^{a}$ \\ Nicolas Treich ${ }^{\mathrm{a}, \mathrm{b}}$
}

January 2020

Forthcoming in International Review of Environmental and Resource Economics

\begin{abstract}
Research in economics is anthropocentric. It only cares about the welfare of humans, and usually does not concern itself with animals. When it does, animals are treated as resources, biodiversity, or food. That is, animals only have instrumental value for humans. Yet unlike water, trees or vegetables, and like humans, most animals have a brain and a nervous system. They can feel pain and pleasure, and many argue that their welfare should matter. Some economic studies value animal welfare, but only indirectly through humans' altruistic valuation. This overall position of economics is inconsistent with the utilitarian tradition and can be qualified as speciesist. We suggest that economics should directly value the welfare of sentient animals, at least sometimes. We briefly discuss some possible implications and challenges for (environmental) economics.
\end{abstract}

Key words: Animal welfare, environmental economics, agricultural economics, economic valuation, speciesism, ethics, sentience, effective altruism.

JEL codes: Q51, Q18, I30, Z00 (i.e., "other special topics" since there is no specific JEL code referring to "animals").

*Acknowledgements: We thank the editors, three anonymous reviewers, Matt Adler, Emilie Dardenne, Francesca De Petrillo, Loren Geille, Oscar Horta, Brian Tomasik and James Vercammen for useful remarks or discussions. Nicolas Treich acknowledges funding from ANR under grant ANR-17-EURE-0010 (Investissements d'Avenir program), IDEX chair AMEP, FDIR chair and IAST. Corresponding author: Nicolas Treich, nicolas.treich@inra.fr.

a: Toulouse School of Economics, University Toulouse Capitole, France b: INRAE

[Type here] 


\section{Introduction}

Imagine that a super-intelligent species invades Earth. The superior intelligence of these aliens allows them to take over political power. Current living humans cannot make sense of their technology, knowledge, art or culture, nor can they comprehend their moral rules and legal obligations. Alien society is wealthy, egalitarian and to a large extent much better than existing human societies. Some aliens are economists who study how to allocate resources and design incentives. In particular, welfare economists have designed and applied sophisticated fairness concepts, but these concepts only concern aliens, not humans. Alien environmental economists study how to preserve the environment and humans and (nonhuman) animals from extinction, and their studies thus contribute to maintaining biodiversity on Earth. Aliens only police their society. If animals commit violence towards humans in the natural environment, aliens do not interfere. Aliens like to eat humans but they care about human welfare to some extent. For instance, while most humans raised for food live inside big production factories, some are free-range, which is better for their welfare but increases the price of human meat.

The storyline of the invasion of Earth by a superior species is standard in science fiction books or movies, such as The Planet of the Apes. It offers a reversal of perspective and stimulates reflection on issues such as domination and hierarchy between different species. Although our story is pure fiction, we believe the issues it raises are very real and should be taken seriously by economists. Specifically, this paper is motivated by the observation that economics research has been so far almost exclusively anthropocentric. Without excuse nor discussion, economists consider only the welfare of humans in their studies. At best, economists assume that animals have an instrumental, or indirect, value. Animals are typically viewed as resources, parts of ecosystems, inputs to biodiversity or food for humans. Yet, animals are not "things". Unlike rocks, water, trees or vegetables, and like us, most animals have a brain and a nervous system. They can feel pain and pleasure, and many argue that this should matter for welfare analysis and policy making.

This paper emphasizes the need to reconsider our anthropocentric approach in (environmental) economics and to view animals as distinct from the rest of nature. As a starting point in this reflection, we discuss some justifications, possibilities and difficulties for integrating and valuing directly the welfare of animals in economic models. The outline is the following. We start in Section 2 by presenting a brief and selective summary of the longstanding discussions in philosophy regarding the moral consideration of animals. In Section 3, we present a brief overview of the populations of animals as well as their evolution and we discuss the central concept of sentience. Sections 2 and 3 may thus serve as an introduction to the topic for economists broadly interested in animals, and provide several seminal references in philosophy and animal sciences. Then, in Section 4, we describe the extent to which and in what [Type here] 
ways animals have been studied by economists in different subfields, while in Section 5 we present a few early attempts in economics to value directly animals in the social objective. Finally, we offer a short discussion in the concluding section.

\section{The Moral Consideration of Animals in Philosophy}

We find the first traces of concern for the treatment of animals in ancient Greek philosophy. Aristotle, for one, viewed animals as resources and wrote that "we may infer that, after the birth of animals, plants exist for their sake, and that the other animals exist for the sake of man...if nature makes nothing incomplete, and nothing in vain, the inference must be that she has made all animals for the sake of man" (Aristotle 350 B.C.). Even then, however, philosophers began to question whether animals do deserve moral consideration. Socrates, in Plato's The Republic: "Would this habit of eating animals not require that we slaughter animals that we knew as individuals, and in whose eyes we could gaze and see ourselves reflected, only a few hours before our meal?" (360 BC).

Although other famous philosophers such as Plutarch and Porphyry also questioned meat eating habits, skepticism regarding the moral status of animals remained the common view for centuries. René Descartes, in a letter to Henry More of 5 February 1649 , famously thought of animals as automata or machines: "it seems reasonable since art copies nature, and men can make various automata which move without thought, that nature should produce its own automata much more splendid than the artificial ones. These natural automata are the animals." Concern for animal interests picked up significant steam in the Enlightenment era. Jean-Jacques Rousseau (1755) introduced the concept of "sensibilité" or sentience. Voltaire (1764) was unconvinced by Descartes' reasoning and wrote a harsh critique. The early utilitarians, such as Jeremy Bentham and John Stuart Mill were particularly influential. Bentham (1780), for instance, argued that when considering whether to value animal interests intrinsically, we should keep in mind that "The question is not, Can they reason? Nor Can they talk? But, Can they suffer?". Here Bentham is invoking the "sentientist view of moral considerability" (Gruen 2017). The ability to experience positive or negative states such as happiness and suffering is often put forward as the fundamental criterion of moral consideration.

Such views are also held by contemporary utilitarians. Probably the most famous, Peter Singer, author of the seminal book Animal Liberation (1975), argued that because animals are sentient, they have interests (such as the interest in not suffering). In his view, ignoring animal interests is a form of arbitrary discrimination akin to racism. After Richard Ryder first coined the term, Peter Singer popularised the concept of "speciesism" in the following form: "the racist violates the principle of equality by giving greater weight to the interests of members of his own race, when there is a clash between their interests and the interests of those of another race.

[Type here] 
Similarly the speciesist allows the interests of his own species to override the greater interests of members of other species. The pattern is the same in each case."

A central argument in Singer's writings is called "the argument from marginal cases". In short, if one believes that humans have moral value, but animals do not, then it is likely that there is an inconsistency in the reasoning behind it. For example, one can claim that animals do not have moral value because they do not possess a certain level of intelligence. The logical consequence would be that humans without that level of intelligence also do not have moral value (such as babies, mentally handicapped, people with Alzheimer's disease etc.). Moreover, if animal welfare counts, there is the question of the trade-off between human and animal welfare, and in particular the thorny question of meat eating. On this matter, Singer (1980) argued that utilitarianism logically implies vegetarianism as "the pleasures of taste - which are not the same as the pleasures of eating - are relatively trivial by comparison with the interests of, say, a pig in being able to move freely, mingle with other animals, and generally avoid the boredom and confinement of factory farm life".

Enlightenment rights theorists, such as Immanuel Kant (1780), by contrast, thought that animals should not be valued intrinsically. They are not part of his categorical imperative. More recently, deontologists have been more sympathetic to animals. John Rawls (1971) and Robert Nozick (1974), for instance, believed that animals' welfare should be given some weight, conditional on there being no infringement on human rights. Tom Regan (1983), perhaps the most well-known animal rights philosopher, believed that as animals are "subjects-of-a-life", who "want and prefer things, believe and feel things, recall and expect things. And all these dimensions of our life, including our pleasure and pain, our enjoyment and suffering, our satisfaction and frustration, our continued existence or our untimely death-all make a difference to the quality of our life as lived, as experienced, by us as individuals. As the same is true of ... animals ... they too must be viewed as the experiencing subjects of a life, with inherent value of their own." Therefore, Regan argues, certain animals in principle should have the same rights as humans. Gary Francione (2008) or Will Kymlicka and Sue Donaldson (2011), among others, have also been proponents of these kinds of arguments, arguing that animals should not be the property of humans. ${ }^{1}$

The aforementioned philosophers are clearly not representative of philosophers in general (for one, many schools of moral thought have not been mentioned). However, some survey studies of academic philosophers provide additional information on their attitudes towards animals. Joshua Rust and Eric Schwitzgebel (2014) find for instance that ethicists are more likely to think that it is wrong to eat

\footnotetext{
${ }^{1}$ For reasons of space, we cannot further develop modern approaches in philosophy on the moral consideration of animals (see for instance Sunstein and Nussbaum (2004), Holtug (2007), Rowlands (2009) and Gruen (2017), or the following website: https://www.animal-ethics.org/).

[Type here]
} 
animals and actually eat fewer animals than other academics. $60 \%$ of ethicists thought that eating mammal meat was bad to some degree, significantly more than other philosophers (45\%) and professors (19\%). The Rust and Schwitzgebel study was replicated for philosophers in German-speaking countries (Schönegger and Wagner 2019). Again, moral philosophers were more likely to say that eating meat was immoral and consumed less meat than the other groups. ${ }^{2}$

More generally, the majority of philosophers regardless of their tradition, (consequentialism, deontology, virtue ethics, phenomenology, etc.) who have expressed an opinion on animal interests, think that they have positive intrinsic value and deserve some moral consideration (Armstrong and Botzler 2003). It therefore seems that moral philosophers are more sympathetic to valuing animals intrinsically than most other scholars. The takeaway for economists is that incorporating animal interests directly into the social objective represents a plausible improvement to normative analysis. This is particularly true when considering that consequentialism, upon which normative economic analysis is almost exclusively founded, has a strong history of taking animal interests seriously. As Johansson-Stenman (2018) says: "It is somewhat paradoxical that economics, which from an ethical point of view almost entirely builds on consequentialism, is nevertheless built on assumptions that resemble Kant's (or Carruthers's) rather than Bentham's (or Singer's) perception with respect to animal suffering."

\section{Animals in this World}

We have emphasized in the previous section that many philosophers believe that animals deserve moral consideration. Since animals are everywhere in this world, this likely has implications for human economic decision and policy making. To get a better sense of what these implications might be, we first outline in this section the most populous categories of animals, and present some recent evolutions of these populations. We also discuss the central concept of animal sentience. Unfortunately, this section is necessarily highly incomplete and speculative. For population numbers, wild animal estimates are particularly uncertain and we often provide rough order of magnitude estimates. ${ }^{3}$ For issues regarding sentience, we emphasize the lack of a global definition, scientific uncertainty and methodological limitations.

\footnotetext{
${ }^{2}$ We are not aware of studies about economists' opinions and habits about meat eating. Data obtained from the European Association of Environmental and Resource Economists (EAERE) conference organizers over the last few years indicate that about $15 \%$ of conference participants order vegetarian meals (personal communication).

3 It seems that biologists have not invested a lot of effort trying to estimate animal population numbers. Kevin Gaston and Tim Blackburn (1997) write that "Attempts to assess the magnitude of global biodiversity have focussed on estimating species richness. [...] The total number of individual organisms in the world. [...] has been a largely ignored statistic." Brian Tomasik, who has informally estimated wild animal populations, supports this view, citing an article in Nature Communications (Veresolgu, Halley and Rillig 2015): "This Nature Communications article uses my estimates of numbers of wild animals in one of its figures: "Densities for aboveground organisms originated from [Type here]
} 


\section{Animal categories}

Pets

While it is hard to find global numbers for pets, some figures give a sense of the order of magnitude. There are about 300 million pets in the U.S. with the most common being fish (105 million), cats (86 million) and dogs (78 million) (Green 2016). $48 \%$ of U.S. households own a dog, and $38 \%$ own a cat (APPA 2018). At the EU-28 level, in 2016, 18\% of households own a dog, 26\% own a cat, and around $35 \%$ own any kind of pet (FEDIAF 2017). A naive extrapolation assuming the rate of pet ownership around the world is the same as in the U.S. would suggest a global pet population of 6.8 billion.

\section{Animals used in science}

In 2005, there were around 115.3 million vertebrate lab animals used per year (Taylor et al. 2005). However, the number of animals alive at any given time is likely to be less than 100 million (Fraser and MacRae 2011). A large number of invertebrates are also used, but the number of animals does not appear to have been estimated.

\section{Farm animals/livestock}

Livestock outnumber laboratory animals and pets. The Food and Agriculture Organisation (FAO) of the United Nations estimates the total population to be over 30 billion. The breakdown of these numbers into species is reproduced below.

\begin{tabular}{|l|l|}
\hline Species & Global Population, millions (2017) \\
\hline Total & 30,243 \\
\hline Chickens & 22,847 \\
\hline Cattle & 1,492 \\
\hline Sheep & 1,202 \\
\hline Ducks & 1,151 \\
\hline Goats & 1,034 \\
\hline Pigs & 967 \\
\hline Turkeys & 459 \\
\hline Geese and guinea fowls & 371 \\
\hline Rabbits and hares & 309 \\
\hline
\end{tabular}

projections of global population estimates for taxonomic groups found in 'Tomasik B. (2014) How Many Wild Animals Are There?'." This reinforces my impression that there has been surprisingly little

$$
\text { of aggregate }
$$
wild-animal populations."

https://www.facebook.com/brian.tomasik/posts/759423432232

[Type here] 


\begin{tabular}{|l|l|}
\hline Buffaloes & 201 \\
\hline Horses & 61 \\
\hline Asses & 46 \\
\hline Camels & 35 \\
\hline Pigeons, other birds & 27 \\
\hline Rodents, other & 19 \\
\hline Mules & 9 \\
\hline Camelids, other & 9 \\
\hline Animals live nes & 1 \\
\hline
\end{tabular}

Table 1. Estimated numbers of animals in agriculture. Numbers are rounded to the nearest million. Source: FAO (2017).

\section{Farmed fish}

Kelly Witwicki (2019) estimates that there are 111.3 billion farmed fish alive at any given moment. Alison Mood and P. Brooke (2012) estimate that 37 to 120 billion fish are farmed annually.

\section{Wild animals}

Birds - Gaston and Blackburn (1997) use multiple methods which all give "surprisingly consistent estimates of a global bird population of between 200 billion and 400 billion individuals". Other estimates find populations of between 100 billion and 400 billion (Fisher and Peterson 1964, de Juana 1992). Gaston, Blackburn and Kees Klein Goldewijk (2003) estimate the number of breeding birds at 86.7 billion. This coheres with the larger overall bird population.

Mammals - Gaverick Matheny and Kai Chan (2005) use wild mammal densities that correspond to 2.25 wild bird densities. ${ }^{4}$ Using the population estimates of 200 billion to 400 billion birds, this yields 450 billion to 900 billion mammals.

Reptiles - Tomasik (2009) uses estimates of reptile population density by Ishwar, N.M, Ravi Chellam and Ajith Kumar (2011) and Douglas Raegan and Robert Waide (1996) along with estimates of the total global area of tropical regions from Gaston et al. (2003), to calculate approximate worldwide reptile populations. He suggests that there are between 100 billion and 10 trillion reptiles.

\footnotetext{
${ }^{4}$ This is very rough and possibly an underestimate. The authors write: "Based on a British study by Gaston and Evans (2004) and Harris et al. (1995), here we assume the densities of wild mammals are 2.25 times those of wild birds for each land-use type. Applied to other continents, this is probably a significant underestimate, as Peters (1983, p. 167) records densities for some individual North American mammal species of over 10,000 individuals per square kilometer."

[Type here]
} 
Amphibians - Tomasik (2009) extrapolates from various estimates of local amphibian population densities calculated by Karthikeyan Vasudevan, Ajith Kumar and Ravi Chellam (2001), Vasudevan, Kumar, Barry R. Noon and Chellam (2008), Ching-Yu Huand and Ping-Chun Lucy Hou (2004) and Raegan and Waide (1996) to estimate a global amphibian population of 100 billion and 10 trillion.

Fish - Worldwide fish biomass is estimated to be in the vicinity of 1 to 2 billion tonnes (wet mass) (Wilson et al. 2009, Jennings et al. 2008). Some suggest that early estimation techniques which involved trawling nets greatly underestimate fish biomass. Newer estimates involving acoustic methods suggest that the biomass of mesopelagic fish alone is 10 billion tonnes (Kaartvedt, Staby and Aksnes 2012, Irigoien et al. 2014). Mood and Brooke (2010) find that 77.4 million tonnes of fish corresponded to 0.97 to 2.74 trillion individual fish. Naively applying these conversion rates to the 10 billion tonnes figure gives worldwide wild fish population estimates of 125.3 trillion to 354 trillion individual fish. Using a different estimation method, Yinon Bar-On, Rob Philipps and Ron Milo (2018) estimate approximately one quadrillion fish. ${ }^{5}$

Other (insects etc.) - Less cognitively complex animals are many orders of magnitude more populous than the previous groups (Williams 1960, Tomasik 2009). In the interest of space, we do not conduct a review but note that even very low probabilities of moral consideration (or very weak sentience) would still imply endowing them some weight in our decision making.

\section{Some evolutions and human-animal interactions}

The above data are static and uninformative regarding the evolution of animal populations and the role of human-animal interactions. In the Anthropocene era, the interactions of humans with animals are numerous and multifaceted. Humans have wide impacts on animal populations and the environments in which they live. The recent global assessment report on biodiversity and ecosystem services of the Intergovernmental Science-Policy Platform on Biodiversity and Ecosystem Services (IPBES 2019) emphasizes that the rate of species extinction is tens to hundreds of times higher than the average rate over the past 10 million years and is accelerating. About 1 million species are at risk of extinction nowadays, half of those are plants or animals and half are insects. IPBES (2019) identify five main direct drivers of

\footnotetext{
${ }^{5}$ The authors explain their method: "In order to estimate the total number of fish, we rely on our estimate for the total biomass of fish of $\approx 0.5 \mathrm{Gt} C$ and estimate the mean mass of an individual mesopelagic fish, as mesopelagic fish are the main contributor to the total fish biomass. In order to estimate the mean mass of an individual mesopelagic fish, we use empirical allometric relations between fish length and mass, along with ranges for the lengths of different mesopelagic fish species (301). From the available data, we estimate an average individual mass of $\approx 0.5 \mathrm{~g} C$ per fish (...). This brings our estimate of the total number of mesopelagic fish to $\approx 10^{15}$ fish."
}

[Type here] 
biodiversity loss: changes in land and sea use; direct exploitation of organisms; climate change; pollution; and invasion of alien species.

Humans have had a significant effect on the balance of life on Earth, reducing habitats and driving some species to extinction. Bar-On, Philipps and Milo (2018) offer different metrics to gauge the human impact on animal populations. They compile hundreds of local and global recent studies to compute the biosphere biomass composition in terms of gigatons of carbon. Figure $1 \mathrm{~A}$ shows that plants dominate terrestrial and marine life forms, accounting for over $80 \%$ of all living biomass. All animals, namely mammals plus fish, insects, worms, birds, and others, account for only $0.37 \%$ of biomass. Figure 1B shows that fish represent more than 100 times the biomass of humans, and humans represent almost 100 times the biomass of wild (terrestrial) mammals. Note that the biomass of livestock is almost twice that of humans. Figure 2 underlines the recent prevalence of domesticated animals' biomass over human and wild animal biomass, further illustrating the wide indirect impact of humans on the planet through their food production.

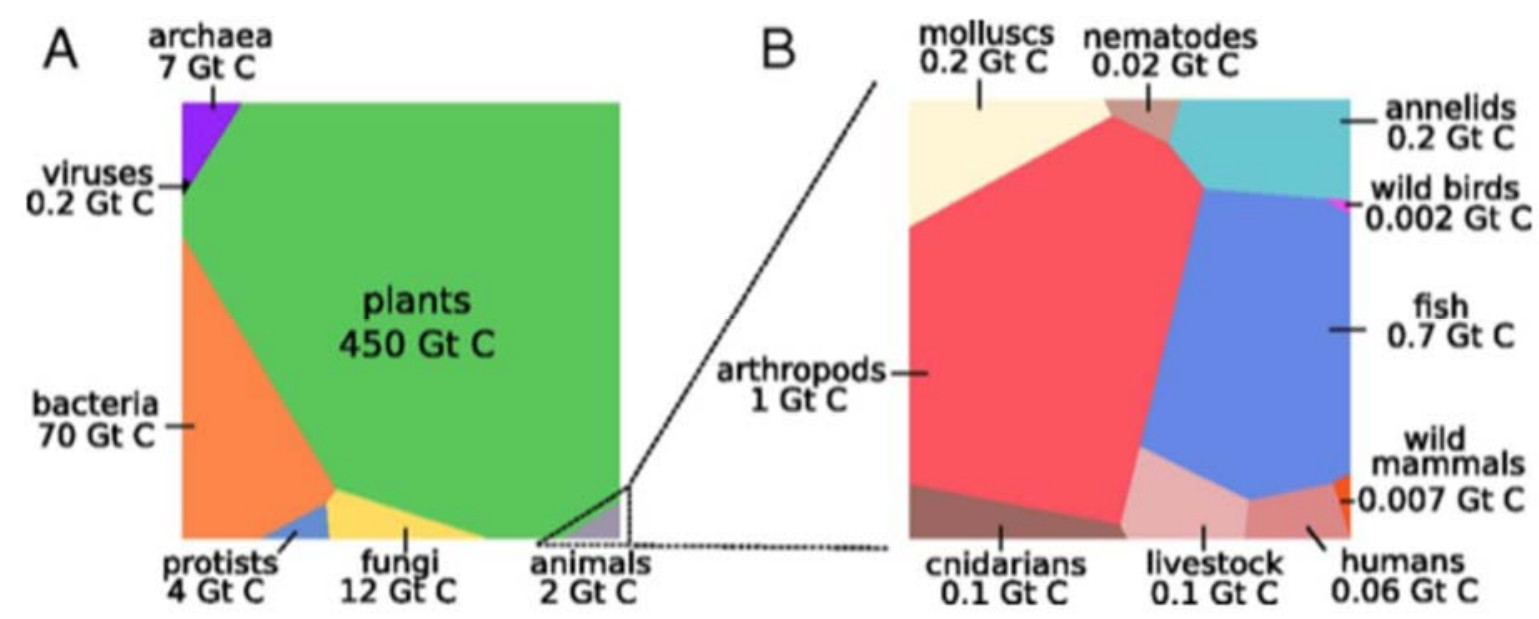

Figure 1 (Bar-on, Philipps and Milo 2018). Graphical representation of the global biomass distribution by taxa. $(A)$ Absolute biomasses of different taxa are represented using a Voronoi diagram, with the area of each cell being proportional to that taxa global biomass (the specific shape of each polygon carries no meaning). (B) Absolute biomass of different animal taxa. Related groups such as vertebrates are located next to each other.

[Type here] 


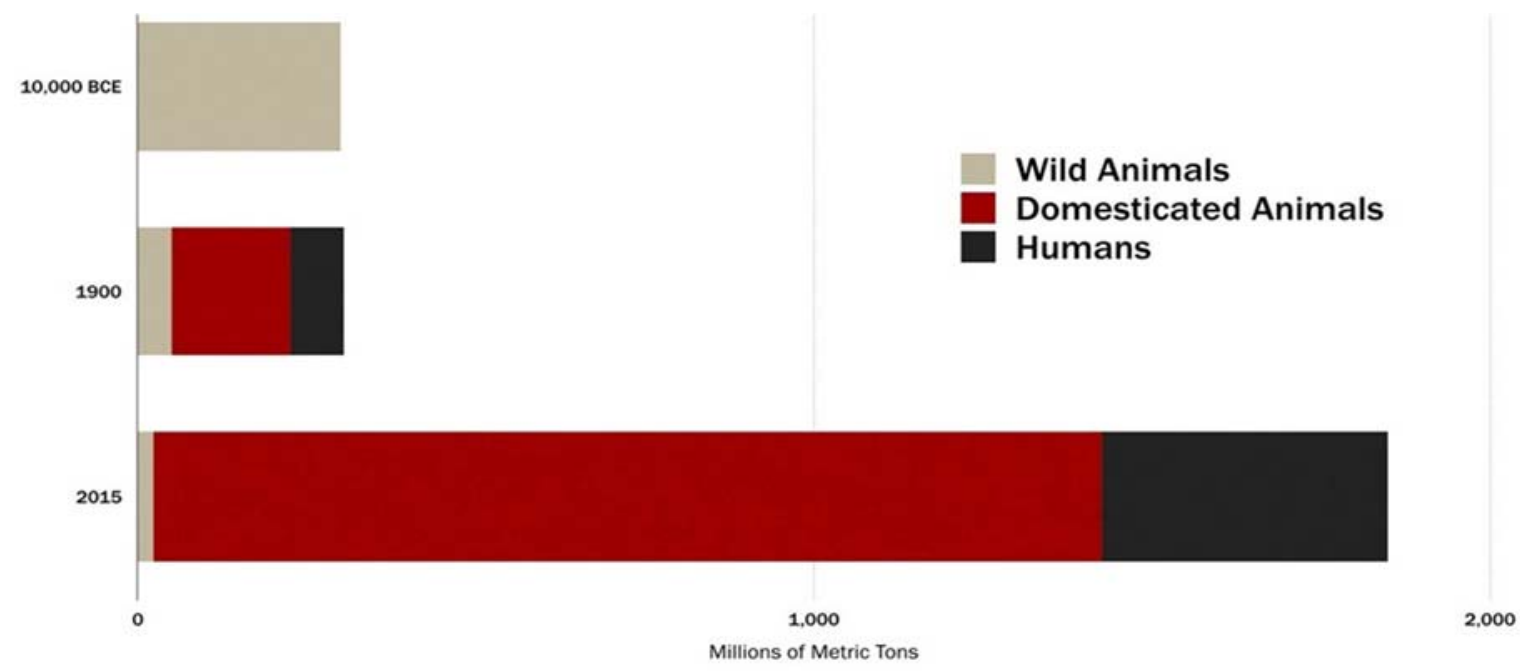

Figure 2. Estimated biomass of wild animals, domesticated animals, and humans. Source: Vaclav Smil (2013). Data prepared by Nathan Hagens and Paul Chefurka: www.resilience.org/stories/2018-08-30/the-way-of-exploitation-can-we-do-better/

\section{Sentience}

As aforementioned, sentience is often presented as the fundamental criterion for moral consideration. However, a clear and commonly accepted definition of sentience is lacking. According to Donald Broom (2014), sentience is "having the awareness and the cognitive ability necessary to have feelings" and to "perceive and experience". Using this definition, many studies in animal sciences are relevant to assess sentience. This is what the journal Animal Sentience, wholly dedicated to the notion, is trying to do. It includes research on animal cognition, emotions, pain, metacognition, consciousness and ability to learn, remember, plan and recognize other individuals,. The notion of consciousness is central but notoriously hard to study. David Chalmers explains: "The really hard problem of consciousness is the problem of experience. When we think and perceive, there is a whir of information processing, but there is also a subjective aspect. As Nagel (1974) has put it, there is something it is like to be a conscious organism... It is undeniable that some organisms are subjects of experience...It is widely agreed that experience arises from a physical basis, but we have no good explanation of why and how it so arises." (Chalmers 1995).

We have no good understanding of the mechanism by which consciousness arises, and it is, therefore, difficult to know whether other animals are sentient. For complex species with physiological similarities to humans, this problem is less important because physiological correlates of different conscious states in humans can be measured in such animals (Edelman, Baars and Seth 2005). Doing so provides strong evidence of sentience for mammals, and even birds and cephalopods (Baars 2001, Edelman, Baars and Seth 2005). Temple Grandin (2006) notes the similarities between pig brains and our own: "I was astounded to learn that the limbic system, [Type here] 
which is the part of the [human] brain associated with emotion, looked almost exactly like the limbic system of a pig's brain." Another part of the brain, the neocortex also plays a central role in emotions, along with perceptions, abstraction, and language in mammals.

There is also evidence of consciousness in animals such as birds and octopuses. The well-known Cambridge Declaration on Animal Consciousness (2012) states that: "The absence of a neocortex does not appear to preclude an organism from experiencing affective states. Convergent evidence indicates that non-human animals have the neuroanatomical, neurochemical, and neurophysiological substrates of conscious states along with the capacity to exhibit intentional behaviors. Consequently, the weight of evidence indicates that humans are not unique in possessing the neurological substrates that generate consciousness. Nonhuman animals, including all mammals and birds, and many other creatures, including octopuses, also possess these neurological substrates."

As the physiological correlates of consciousness begin to differ more widely from those found in humans, such as in reptiles, amphibians, and fish we can hardly rely on physical similarities (Seth 2016). Evidence for sentience in these species is, therefore, weaker (Butler and Cotterill 2006). When we consider less complex species like terrestrial arthropods, we are forced to rely even more on mechanistic explanations of consciousness as opposed to physiological similarity, none of which are particularly satisfying. Anil Seth (2016) argues that we should apply the precautionary principle and therefore take seriously the possibility that such animals are conscious, while Simon Knutsonn and Christian Munthe (2017) put forward "A virtue of precaution regarding the moral status of animals with uncertain sentience."

Animal cognitive capacities vary widely depending on the natural environment such as the diet or the use of foraging techniques (Rosati 2017), as well as social life (Dunbar and Shultz 2007). Evan MacLean et al. (2014) emphasize that differences in absolute (not relative) brain volume best predict performance across species. However, others argue that total brain size "has been shown to be a poor indicator of both intelligence and sentience" and "it should be the complexity of the brain's function that is considered in regards to welfare, rather than its size" (Proctor 2012). Some animal species function very well even with small brains. Small animals usually have smaller brains than large animals, but their ability to quickly process information and make decisions is usually greater. Various comparison studies across animals indicate that the neocortex size is proportional to the size of the group (Broom 2014). Rogers and Kaplan (2004) think that a better measure of brain capacity "might be the number of neurons versus glial cells, number of dendrites per neuron, or the number of synaptic connections per neuron (...), or some other measure reflecting neural mechanisms." They further note that only a "handful of species have been researched in depth, and current findings would suggest that [Type here] 
many more species might be found to have exceptional cognitive abilities, if we only looked."

Moreover, there is no strong reason to expect a systematic relation between cognitive and physical ability to suffer. Richard Dawkins (2011) for instance argues: "Isn't it plausible that a clever species such as our own might need less pain, precisely because we are capable of intelligently working out what is good for us, and what damaging events we should avoid? Isn't it plausible that an unintelligent species might need a massive wallop of pain, to drive home a lesson that we can learn with less powerful inducement? At very least, I conclude that we have no general reason to think that non-human animals feel pain less acutely than we do, and we should in any case give them the benefit of the doubt." In any case, if animals feel pain, they should learn to avoid it, and observing their avoidance behavior and reactions should be informative. Animal behavior is currently used in the (pre-)clinical assessment of pain, injury and disease (Dawkins 2004). More generally, a promising research area uses, as in revealed preference studies of humans in economics, observed animal behavior to assess animal welfare (see, e.g., Mason, Cooper and Clarebrough 2001). Many studies even indicate that some animals understand how to use money as a metrics for exchanging food or else (De Petrillo et al. 2019).

Another example of the difficulty of studying sentience scientifically is the famous "mirror test" designed to study self-recognition or self-awareness (Gallup 1970). In the classic mirror test, an animal is anaesthetized and then marked on a part of the body that the animal cannot see. When the animal recovers, it faces a mirror. If the animal touches or investigates the mark, it indicates that the animal perceives the reflected image as itself, rather than of another animal. Only a few species pass the test including great apes, elephants, dolphins, sea lions, orcas, magpies. Moreover, several species fail the test, including some species of monkeys, pandas, and dogs. However, there are many problems with the test: some animals fear the mirror reflection, have poor sight, are not curious or interested in the task, etc. Dogs, for instance, pay relatively little attention to other dogs' visual aspects, as they mostly care about how they smell (Rogers and Kaplan 2004). A recent study indicates that a species of fish may pass the test (Kohda et al. 2019), and concludes that this finding challenges our common interpretation of the mirror test: "Do we accept that these behavioural responses, which are taken as evidence of self-recognition in other species during the mark test, lead to the conclusion that fish are self-aware? Or do we rather decide that these behavioural patterns have a basis in a cognitive process other than self-recognition and that fish do not pass the mark test? If the former, what does this mean for our understanding of animal intelligence?".

What about plants? Plants are fundamentally different: They do not have a brain, eyes, nervous or digestive systems. It is not even clear that plants are individuals [Type here] 
since they are divisible. Many plants propagate through asexual reproduction. Some plants, such as the olive tree can live for several thousand years, while others, such as lianas, can be more than a hundred meters long. The botanist Françis Hallé talks about the "radical otherness" of vegetal life compared to animal life. Nevertheless, many popular writers or artists but also life scientists have suggested that plants have emotions, and possess a form of cognition. The proponents of the recent "plant neurobiology" approach draw parallels between electrical signaling in plants and nervous systems in animals, and hypothesize that plants can learn and possess consciousness, feelings, and intentionality. However, this hypothesis does not seem to resist proper scientific investigation. There is a basic evolutionary reason why this is the case. As plants do not move and do not react quickly, it would be inefficient for them to have these energy-intensive mental faculties without getting much benefit from them. In a recent synthesis paper, Lincoln Taiz and coauthors (2019) criticize in a systematic fashion plant neurobiologists' findings, and consider that 'the likelihood that plants, with their relative organizational simplicity and lack of neurons and brains, have consciousness to be effectively nil."

The bottom line is that, despite high levels of scientific uncertainty and complexity, and despite ongoing discussions regarding the definition and characterization of sentience, there are no strong scientific or logical reasons for thinking that only humans are sentient, nor that sentience is a binary notion. It seems much more sensible to consider that sentience is shared by most animals and that it is continuous and varies in degree. As Broom (2014) writes: "Animals vary in the extent to which they are aware of themselves (DeGrazia, 1996) and of their interactions with the environment, including their ability to experience pleasurable states such as happiness and aversive states such as pain, fear and grief. This capacity may be referred to as their degree of sentience". However, sentience is probably limited to animals with current scientific knowledge indicating that the likelihood that plants are sentient is close to zero.

\section{Animals in Economics}

There are remarkably few published papers in leading economics journals on animal welfare. Figure $3 \mathrm{~A}$ shows that there are merely 32 recorded papers in the top 50 economic journals according to Microsoft Academic's database, with the first appearing in 1984 (see the Appendix for details). Since then interest in animal issues seems to have increased slightly, but there have nevertheless not been more than four relevant papers published in the selected journals for a given year. When we restrict the search to the commonly accepted top 5 economics journals there are no hits at all. The most cited paper from Figure $3 \mathrm{~A}$ is Corporate social responsibility in the supply chain: An application in the food industry (Maloni and Brown 2006). As the title suggests, animal welfare is not the main focus of this paper. This kind of vague relationship to animal issues is quite common for the WEB OF SCIENCE ${ }^{\text {TM }}$ [Type here] 
search results (despite using the keywords <animal welfare>, <animal rights>, and $<$ speciesism>), with only around half of the results focussing on animal interests, and many of these through the lens of humans' altruistic valuation.

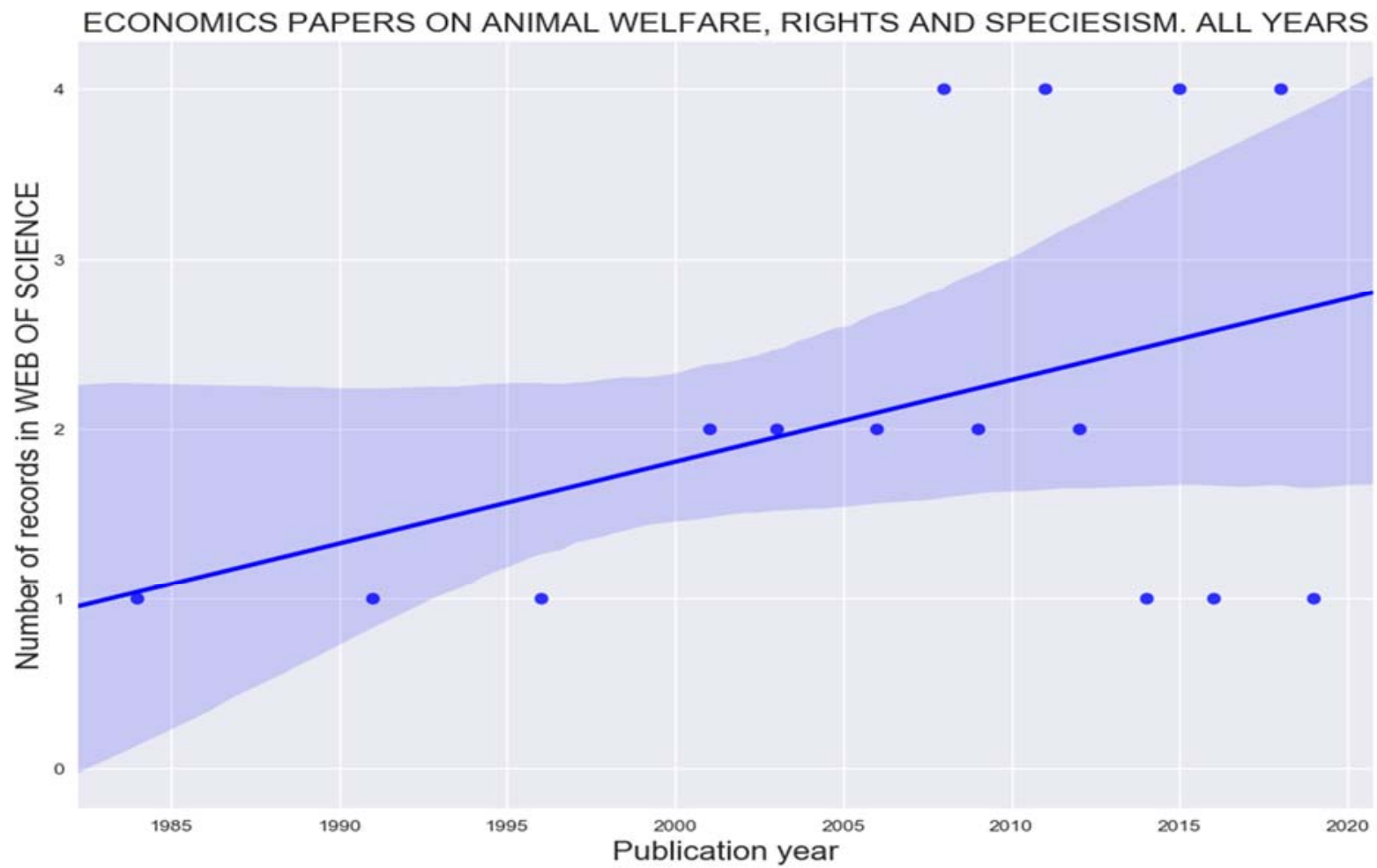

Figure 3A. Economists' lack of interest in animals. Notes Bibliometric search of the WEB OF SCIENCE ${ }^{\text {TM }}$ in July 2019 with the key words <animal welfare> or <animal rights> or <speciesism>; hits are articles published during any year in Microsoft Academic's top 50 economics journals, ranked by their $h$-index for all years.

The Microsoft Academic database is not exhaustive, of course. ${ }^{6}$ Many Journals in the top 50 list are not considered to be important in standard economics, and concern adjacent fields such as management. Hence, Figure $3 \mathrm{~A}$ may even overestimate the study of animals in economics. Figure 3B represents the number of papers using some specific keywords. It suggests that economists have preferred to focus on topics that may seem less important to many, such as "fashion". When animals are studied, it is usually in terms of their use by humans, as for "fishing". Strikingly, the study of the animals' flesh, "meat", dominates the study of their interests, with 290 hits versus 32. Another illustration concerns the JEL codes list pervasively used by economists. As we indicate on the first page, this list does not contain any entry explicitly referring to animals. For the sake of comparison, it contains an entry "L67: Other Consumer Nondurables: Clothing, Textiles, Shoes, and Leather Goods; Household Goods; Sports Equipment".

\footnotetext{
${ }^{6}$ One of the key papers we discuss later is absent (Blackorby and Donaldson 1992).

[Type here]
} 


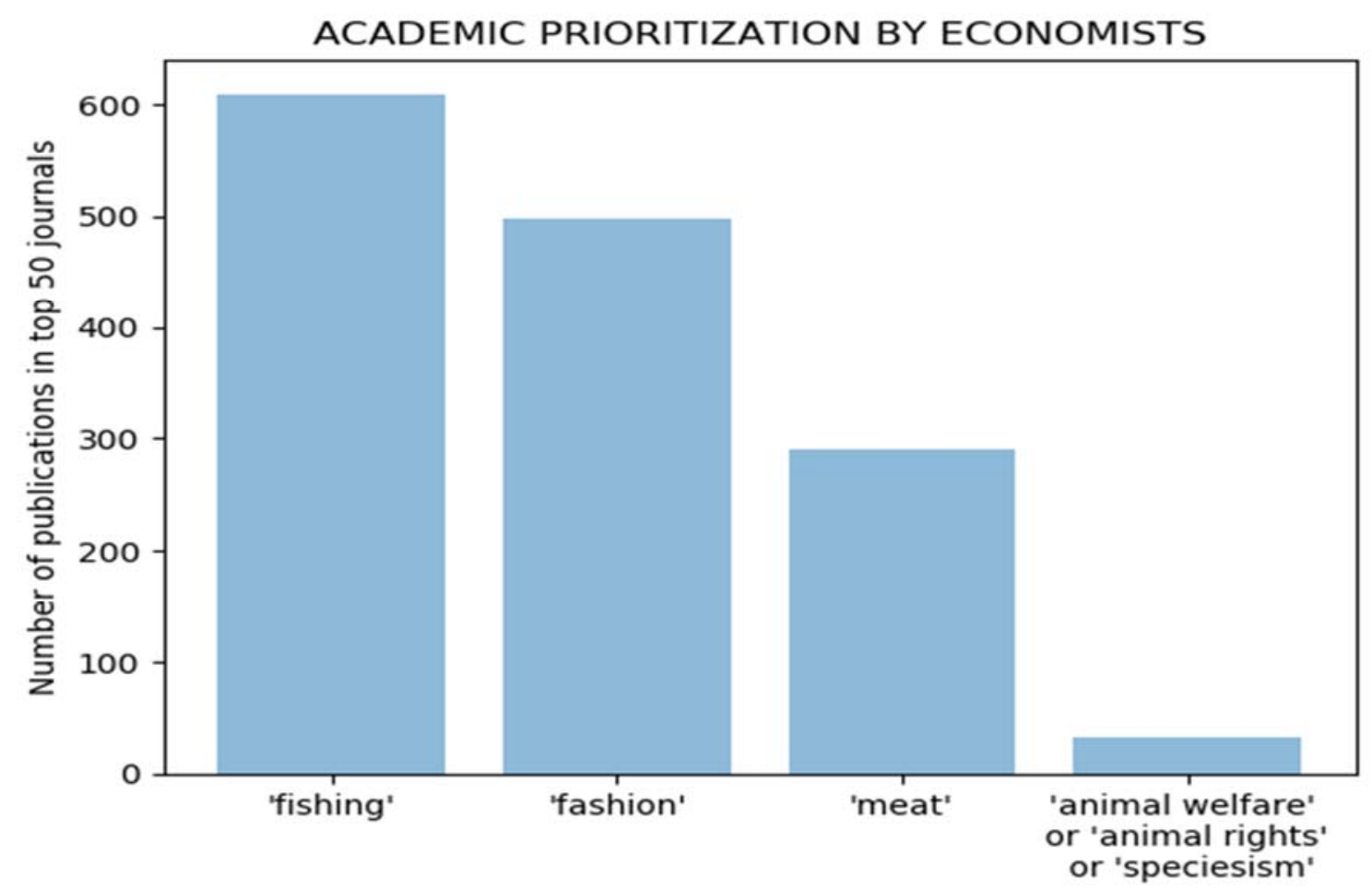

Figure 3B. Number of academic papers by economists on various topics. Notes Bibliometric search of the WEB OF SCIENCE ${ }^{\text {TM }}$ with the key words <fishing>, <fashion>, <meat>, <animal welfare> or <animal rights> or <speciesism>; hits are articles published during any year in Microsoft Academic's top 50 economics journals, ranked by their $h$-index for all years.

Animals are thus largely absent from economics. Economists often talk of "Animal Spirits" not to refer to the subjective experience of animals, but rather to describe human instincts and emotions that influence economic phenomena such as financial markets (Keynes 1936, Akerlof and Shiller 2009). This is the only use of the word animal in Gregory Mankiw's Macroeconomics (2009), and we did not find any reference to animals in Andreu Mas-Colell's classic Microeconomic Theory (1995). An exception concerns the study of animals in lab economic experiments (Kagel, Battalio and Green 1995) or in neuroeconomics (Kalenscher and van Wingerden 2011). This research usually studies similarities in economic and evolutionary theories of human and animal decision making. Many of the behavioral patterns and violations of rationality found in humans are usually found in animals too (Ainslie and Herrnstein 1981, Santos and Rosati 2015). However the main focus of this research is not animal welfare, but human behavior and ultimately human welfare.

In welfare economics, a central concept is the veil of ignorance proposed by John Rawls and John Harsanyi, which is related to the Adam Smith's notion of the impartial spectator. The concept is based on a thought experiment in which people making political decisions must imagine that they know nothing about their own identity, so that they can overcome their self-serving bias and in turn be morally impartial. Browsing various examples given in the literature, people are asked to imagine that they do not know their gender, ethnic background, economic status, [Type here] 
class, abilities or talents; they can be slaves, physically handicapped, mentally retarded and so forth, but they usually cannot be animals. Many mental barriers are overcome in this thought experiment, but not that of species. The "impartial" spectator is thus usually speciesist. More generally, social choice and public economics, some major historical fields in economics, have essentially ignored animals. It is not clear why animals have been deemed to not fit into the research agenda of economists working in these fields, but this is revealing given how extensively and rigorously issues such as fairness, inequality and welfare have been explored in these fields.

\section{Natural resource and environmental economics}

In natural resource and environmental economics, animals are typically treated as inputs or consumption goods. Animals are therefore valued indirectly, insofar as the consumption (e.g. recreation, input to production, food) of animals leads to benefits for humans. Animals are a particular type of stock: renewable resources, because they can reproduce. A large portion of the literature on renewable resources, such as the study of fisheries, focuses on the "harvesting of animal species" (Perman et al. 2003). Another focus is on biodiversity, which is "important in the provision of environmental services to economic activity in a number of ways" (Perman et al. 2003). Here again, animals are also valued indirectly, as an input to biodiversity and thus human welfare.

Valuation is also a major topic in environmental economics. This often involves measuring the economic value of use (direct and indirect) of animal species, along with non-use values, such as valuing the existence of a species, or possibly animal welfare. This is usually done via willingness-to-pay (WTP) studies (Harris 2006). There exist quite a number of contingent valuation studies for the preservation of wild animals for instance (MacMillan et al. 2002, Loomis 2006, Boardman et al. 2011). These studies investigate the (ir)rationality of participants who may be subject to various standard psychological biases, such as "scope insensitivity", e.g. valuing the lives of 10 birds equivalently to 1,000 birds; "proportion dominance", valuing each life saved more in smaller populations (Bartels 2006); or the "identifiable victim effect", placing more value on salient individual victims compared to statistical lives. More specifically, environmental valuation studies also raise the question about whether participants "correctly" assess animal welfare, and in particular whether these assessments are subject to biases due to anthropomorphism, (non)familiarity with certain animals, misrepresentations as well as genetic distance (Miralles, Raymond and Lecointre 2019). Moreover, these approaches do not solve the fundamental question of how to account for the intrinsic value of animals, independent from humans. Steven McMullen (2016) concludes that "while it is relatively simple to expand economic theory to include altruistic human preferences 
in favor of animal interests, this approach ends up adding little in actual applications (...) and carries little ethical weight outside of an anthropocentric worldview".

In natural resource economics, analysis often focuses on optimal behaviors (e.g. consumption, pollution) through time because current behavior affects future resource availability, with the extreme case being, in the case of animals, extinction. This is again done from an anthropocentric perspective, with a focus on "inducing market systems of economic organisation to take proper account of the ways... that what happens to these plants and animals affects human utilities." (Perman, Ma, McGilvray and Common 2003). The economic impact of invasive species is also studied along with that of endangered species (Olson 2006, Gardener and Shogren 1998). Endangered species legislation can be viewed as society acting in the interest of future generations, but also as humans agreeing with the principle that animals have the right to exist, regardless of the economic cost that it imposes on society. The legislation can certainly be very costly (Ando and Langpap 2018). Nevertheless, the approach is not concerned by the wellbeing of individual animals per se, but rather by the (non-)existence of animal species. Furthermore, the environmental benefits of preservation are usually computed using an anthropocentric method.

\section{Agricultural economics}

Here animals are treated as inputs to the production of animal products such as meat, milk or eggs. The word "livestock" used in agricultural economics is revealing: animals are treated as living stocks. The only mention of animals in the subject index of the Handbook of Agricultural Economics is "animal wastes" (Gardner and Rausser 2002). Topics of interest include the valuation of food safety in meat (Mørkbak, Christensen and Gyrd-Hansen 2009), examining the effect of information about animal welfare on consumer WTP for animal-based products (Napolitano et al. 2008), estimating potential economic and environmental improvements to farms (Asmild and Hougaard 2007), and assessing consumer preferences regarding antibiotic use in animal production (Lusk, Noorwod and Pruitt 2006). There are several dozen studies about WTP for farm animal welfare in agricultural economics capturing indirectly humans' altruistic valuation of animal welfare (Nocella, Hubbard and Scarpa 2009, Lagerkvist, Johan and Hess 2010).

Jason Lusk and F. Bailey Norwood in a series of papers and an excellent book have focussed on questions concerning farm animal welfare. They have for instance examined animal welfare as a public good and outlined cost-benefit analysis taking into account farm animals, conducted revealed preferences research, estimated the cost of animal welfare improvements, studied vegetarianism, and Lusk has suggested creating a market for animal welfare using credits, analogous to emissions trading schemes (Lusk and Norwood 2011a, Lusk and Norwood 2011b, Lusk 2011, Norwood and Lusk 2011). In almost all of their studies, however, animals'

[Type here] 
welfare is only accounted for indirectly through consumers' preferences. In the same vein, Harald Grethe (2017) discusses consumer demand for animal welfare, emphasizing the "preference gap" between consumer and citizen perspectives. A possible explanation for this gap is the cognitive dissonance leading to the "meat paradox" hypothesis: consumers form self-serving beliefs about animal welfare to reduce the moral guilt associated with their meat consumption (Hestermann, Le Yaouanq and Treich 2018).

\section{Ecological economics}

As illustrated in Section 2, natural scientists and in particular ecologists are usually interested in the number of animals and work at the species' level. The focus is thus on the populations and ecosystems' natural equilibria, but not on individuals, and especially not on the welfare of individual animals. Moreover, some argue that natural scientists have an idyllic view of natural processes, and of the preservation of nature (Horta 2010, Dorado 2015, Faria and Páez 2015). These views have probably impacted ecological economics which also tends to focus on population issues and environmental preservation, and do not typically study animals' welfare. A central concept in ecological economics is the tragedy of the commons. Ecologist Garrett Hardin (1968) famously explains in the context of pasture grazing: the tragedy comes from each herdsman asking, "What is the utility to me of adding one more animal to my herd?", leading to overgrazing because the negative grazing externality is not internalized by each herdsman. We note however that another sentient being is involved in the tradeoff, without even being considered or discussed in the global commons literature.

Michael Common and Sigrid Stagl (2005) write that "there is no difference at all between ecological economics and neoclassical economics. Both are anthropocentric, as well as utilitarian." (Common and Stagl 2005). Ecological economics pioneers Robert Costanza, Herman Daly and Joy Bartholomew (1991) make this clear when defining sustainability: "Sustainability is a relationship between human economic systems and larger dynamic, but normally slowerchanging, ecological systems in which 1) human life can continue indefinitely, 2) human individuals can flourish, and 3) human cultures can develop; but in which effects of human activities remain within bounds, so as not to destroy the diversity, complexity, and function of the ecological life support system." Other typical topics in ecological economics include examining "animals as open systems" (Common and Stagl 2005), the function of different species, animal food-gathering strategies, ecosystem structure (Daly and Farley 2004), and studying the population dynamics of animal species and the resulting equilibrium.

\section{Directly Valuing Animals in Economics}

[Type here] 
We have emphasized in the previous section that research in economics has essentially ignored the welfare of animals. At best, animal welfare is accounted only indirectly through personal humans' preferences. McMullen (2016) argues that 'the most important reason for economists' silence (...) is that many ethical questions are framed as personal matters, rather than as questions of justice". Yet JohansonStennman (2018) argues that "it is possible, and indeed relatively straightforward, to extend the conventional theory of welfare measurements to the case where animal welfare carries intrinsic weight in the SWF [Social Welfare Function]." In this section, we present as an illustration a few early works in economics that have attempted to value directly animal welfare. These works share a common point: they consider a social planner who acts on behalf of animals. In other words, animals' welfare enters directly into the SWF.

Charles Blackorby and David Donaldson (1992) consider a multi-species model with both humans and animals. The SWF is utilitarian with equal weight on humans and animals, and so can be interpreted as anti-speciesist. Humans produce and consume animals. Production is costly, and humans derive utility from consumption. The novelty is that farm animals' welfare is directly accounted for in the SWF. Because it is an optimal (animals) population issue, Blackorby and Donaldson use critical-level utilitarianism, which allows them to avoid problems associated with total and average utilitarianism. Humans eat either grain or animals, and animals eat grain. Humans can provide more grain than necessary for animals' survival because this increases animals' welfare (but not the quality of meat) at the cost of their own welfare. Blackorby and Donaldson identify several possible optimal solutions in terms of the production and consumption of animals. One solution features minimal animal welfare and high meat consumption, while another solution features vegetarianism, implying that animals will not be produced and thus will not exist. The authors also discuss implementation issues. Since market forces are driven by humans, the optimal solution is not implemented at the equilibrium. If the social planner wants to increase the level of animal welfare, taxing meat is not enough: it decreases the consumption of animals, but animal welfare is still kept at minimum by humans. The authors thus stress that direct control of animal welfare may be necessary.

Blackorby and Donaldson (1992)'s paper is a major contribution to the literature. ${ }^{7}$ However, we must recognize that it proposes a very utilitarian view of animals who only exist for the sake of humans, i.e. because humans like to eat animals. This view is arguably problematic morally. In their seminal book Zoopolis, Will Kymlicka and Sue Donaldson (2011) argue that animals should not be humans' property, and thus should not be raised for humans' consumption. But Kymlicka and Donaldson also

\footnotetext{
${ }^{7}$ It may become, we believe, a seminal paper. Yet it has been mostly overlooked so far in the economics literature. At the time of this writing, i.e. more than 25 years after publication, it is cited only 64 times on GoogleScholar.

[Type here]
} 
contend that this should not imply that this is the end of farm animals. Instead, they support the preservation of humans' relationships with farm animals. They suggest granting them no less than citizenship since farm animals have the capacity to comply with some social norms and to cooperate. Obviously, letting animals satisfy their own preferences would raise various sorts of issues. One concerns the famous "liberal paradox", as there may be a conflict between animals' preferred choices and humans' views about whether animals should count morally and how.

How can animal welfare fit into a SWF? As we said above, Blackorby and Donaldson (1992) consider a utilitarian SWF with equal moral weight for humans and animals. This SWF has the advantage of being simple and satisfying the standard impartiality (or anonymity) axiom. However, it does not seem morally plausible. Assigning the same moral weight to a human and a rat or even an insect is an assumption that few would accept. Moreover, Section 2 provides an argument for setting different moral weights as we argued that the degree of sentience likely varies across species. Hence, an alternative would be, as in Espinosa and Treich (2019), to consider anonymity within species, but not across species; namely to assume a "semispeciest" approach where different species have different moral weights. As a starting point, several animal charities are currently computing "animal welfare weights" to identify priorities in philanthropy. Mark Budolfson and Dean Spears (2019a) propose estimating these weights with the number of neurons in the brain of an average member of a species. With this assumption, they estimate that a human life year is worth about 344 mammal life years, and about 10,700 fish life years. In another paper, they show that this approach may have drastic implications for climate policy, depending in particular on the moral weight given to insects (Budolfson and Spears 2019b).

Farm animals, but also pets and animals used in science, are the property of humans. The works of animal rights scholars such as Francione, Regan or Steve Wise suggest that the issue of property rights is the most important force leading to the exploitation of animals and their resulting poor welfare. In the law, animals are considered as "things" and cannot have rights and duties. In contrast, economists such as Ronald Coase hold a favorable view of property rights. A major contribution of environmental economics is that well-defined property rights can help solve traditional market failures such as the "tragedy of the commons". Property rights may in turn help animals. McMullen (2016) explains for instance that property rights contributed to saving the American bison from extinction and to mitigating with success over-fishing. Animal ownership creates incentives to take care of animals and to limit damages caused to others by the owned animal. But property rights also generate incentives to pursue production efficiency in the farming industry, an objective which is typically not aligned with animal welfare. The intersection of property rights and animal welfare is certainly complex, and is worth further investigation in economics.

[Type here] 
In reference to evolutionary biology, Yew-Kwang $\mathrm{Ng}$ (1995) introduces the term "welfare biology" to mean the study of living things with respect to their welfare. The emphasis here is on wild animals. $\mathrm{Ng}$ identifies three basic questions in welfare biology: "Which species are affective sentients capable of welfare? Do they enjoy positive or negative welfare? Can their welfare be dramatically increased?", and emphasizes that when scientists "use the apparently subjective terms of wellbeing such as welfare... they actually mean fitness for survival or abundance in the number of species concerned, as if the subjective sense of 'welfare' has absolutely no place in science." He goes on and argues that the "time is ripe for the recognition of welfare biology as a valid field of scientific study". Nevertheless, about 25 years after this publication, it does not seem that welfare biology has really taken off as a field of research.

In a recent follow up to $\mathrm{Ng}$ (1995), Zach Groff and $\mathrm{Ng}$ (2019) write that "at least based on evolutionary theory alone, we should be agnostic with regard to whether total suffering will exceed enjoyment or vice versa." The question of the net welfare of animal populations is important because, under a broadly utilitarian framework, it has implications regarding desirable population levels and the direction in which we ought to change population levels at the margin (Gosseries and Meijers 2019). For instance, a positive (resp. negative) farm animal welfare may justify increasing (resp. decreasing) the numbers of farm animals (Espinosa and Treich 2019). Similarly, if we believe that many, perhaps most, wild animals have lives that include more suffering than positive wellbeing, as does Oscar Horta $(2010,2018)$, a reduction of animal biomass might not necessarily be a curse for the animals. Due to their agnosticism on this question, Groff and $\mathrm{Ng}$ (2019) believe that "it makes sense to base one's views on environmental issues on the more known benefits (and costs) of nature for humans." Of course, even if we believe that for animals' sake it would be better to reduce population levels, other considerations, such as civilizational stability and sustainability might push us in the opposite direction.

Welfare biology might recommend specific policies. Motivated by a Kangaroo cull in Australia, Matthew Clarke and $\mathrm{Ng}$ (2006) model the interaction between population dynamics and welfare maximization for animals. They emphasize that "Natural selection favours the maximization of the number of surviving offspring [and] need not result in the maximization of the welfare of individuals in the species". Various species leave many offspring of which just a few survive. The idea is that a lower birth rate may increase animal welfare. To study this, Clarke and $\mathrm{Ng}$ consider the maximization over the birth rate of both intertemporal total and average welfare and study exponential vs. non-exponential growth in the case of a single animal population. They show that optimal birth rates are lower in the case of welfare maximization vs. growth maximization, while the survival rates are higher. This holds for both the total and average welfare criteria. They also explore the case of

[Type here] 
competing populations in a Lotka-Volterra model. In this model, the choice of birth rates does not affect the population sizes at equilibrium, and as a result "welfare could be much higher with lower birth rates without even reducing numbers (at equilibrium)".

These results suggest that it could be legitimate for humans to intervene in nature in order to improve animals' welfare, for instance, to vaccinate or sterilize animals. Tyler Cowen (2003) goes a step further and discusses the issue of predation. He notes that more animals are killed via carnivorism than are sustained by such killing, suggesting that, in general, predators reduce net social utility. There may be exceptions, such as when predators significantly reduce starvation among their prey by limiting population numbers. However, "not all predators benefit their prey at all margins", and "in those cases where predators truly do benefit their prey, we may wish to intervene and provide greater support for the predators. There is no a priori reason to believe that nature has provided a welfare-maximizing balance of power between predator and prey, which again leads us back to the possibility of policing."

This interventionist approach is undoubtedly very controversial. It raises many concerns such as the potential cost of these interventions. Governments typically lack the resources to manage human affairs and enforce regulation. Adding the immense burden involved in managing the animal kingdom seems unrealistic. Anticipating this critique, Cowen notes that policing nature need not be absurdly costly in some cases though, because "Current policies... often subsidize the propagation of carnivorous animals...It would be easy to limit or eliminate these programs, which again suggests that policing nature need not mean sending out a policeman to stop one group of ants from killing another." Indeed, it also does not seem very costly in many cases to assist animals in great suffering or near-death conditions when possible or to develop vaccination or sterilization campaigns (Garrido et al. 2011, Hall, Nixon and Aitken 2017). Another major concern, however, is that of mistakes of human intervention due to lack of knowledge and poor planning. There are many examples of erroneous human interventions in ecosystems leading to ecological catastrophes.

Justifications for human intervention in nature are typically based on utilitarian arguments (such as reducing the sum of suffering in this world, and thus focusing on wild animals because they are so numerous). This has raised various ethical debates. Jennifer Everett (2001) makes an empirical claim against the interventionist argument, contending that "the state of affairs in which predation occurs in nature without regular interference from humans is better than that in which we attempt to prevent it". Martha Nussbaum (2006) believes that the very idea of intervention is repugnant morally. Kymlicka and Donaldson (2011) argue that we should in general intervene less, and not more, in nature in order to respect the autonomy and sovereignty of wild animals on the grounds that they have abilities and rights to self-

[Type here] 
determination. Horta (2013) argues that although Kymlicka and Donaldson (2011)'s position sometimes allows intervention in nature, their suggested limits on intervention are based on false empirical beliefs about animals in the wild whose situation can be "be considered analogous to one of humanitarian catastrophe, or to that of irretrievably failed states." Kymlicka and Donaldson (2013) responded by arguing that these "claims about the apparent incompetence of wild animals to protect their members" are based on "biased accounts of competence" noting that "all societies, human or animal, are likely to fail some tests of competence."

\section{Conclusion}

The field of economics so far has only been concerned by the welfare of humans. In other words, economics research has been speciesist. It is perhaps time to investigate the implications of anti-speciesism in economics. Doing so may lead to stimulating research. The field of welfare economics, broadly speaking, is primarily concerned. Research on whether and how to include animals in the social objective may require the development of novel methodological approaches in the field, which can perhaps be compared to the paradigm shift towards the inclusion of humans' behavioral limitations. Environmental economics can provide an umbrella for some of this economic research on animals. Environmental economics is concerned by nature, and since many animals live in nature, environmental economics is logically concerned by animals. But animals are not solely resources, biodiversity or commodities at the disposal of humans. Biologically, animals are far more similar to humans than plants. Arguably, as many ancient and modern philosophers have stressed, animals should receive moral consideration. This should matter, at least sometimes, in environmental economics.

The challenges to come are obviously important and multiple. More research is required on animal welfare and sentience. Although animal welfare has been of concern for thousands of years in religion, philosophy, and culture, the study of animal welfare using rigorous scientific methods is relatively recent, and a lot remains to be learned. How can animal welfare be improved? How should we define and measure sentience? How should we treat scientific uncertainty regarding which species are sentient? We argued above that sentience is probably better conceived as a continuous concept. How then should we translate this into a social objective? While it is still difficult, if not taboo, to compare the utility of different human beings, the comparison between humans and animals, and among animals themselves, is obviously a daunting ethical task but also complicated practical one. In any case, more research is necessary to link animal sciences to economic studies. For instance, there are only a few papers that compute the costs and benefits of improving animal welfare. Following economic methodology, the development of revealed preferences research based on animal choices is an interesting research avenue both for animal sciences and economics. Moreover, the development of the

[Type here] 
effective altruism movement in the philanthropic world, which prioritizes altruistic actions based on their cost-effectiveness, is a great illustration of how economics can be used in practice to contribute to animal-related issues.

The research agenda is not limited to normative issues such as welfare measurement or social choice. Possible topics at the interface of animal welfare issues and standard environmental economics abound. Let us mention a few. Meat production affects land use, ecosystems and deforestation which all contribute to climate change and biodiversity loss. Cultured meat (that is, meat produced in vitro from animal cells) may be commercialized in a few years with possibly wide reductions of environmental pollution and in the use of land for animal feed and farming. Cruelty-free products and vegan investment funds have emerged and become part of global corporate social and environmental responsibility initiatives. Endangered species legislation is expected to evolve given increasing rates of species' extinction. Hunting and fishing have complex effects on ecosystems and animal populations. Rewilding programs cause externalities for humans but also for other animals. Building cities differently to reduce energy use and pollution from transportation affects urban animal populations such as rats or pigeons. Policies regarding noise and light pollutions might considerably impact animals and their ecosystem. All these complex issues deserve to be addressed with an eye on animal welfare implications.

Animal issues also provide an interesting domain of application in political economy. Groups of farmers and hunters have traditionally been very powerful politically in many developed countries. But animal activists have become better organized and more efficient due to information spreading and facilitated coordination through the internet. The general public is increasingly aware of wild animal extinction issues and of poor animal rearing conditions associated with industrial farming. In many rich countries, the proportion of vegetarians and vegans (usually between 3 to $10 \%$ ) is now greater than that of farmers in the population. Several parties for animals have their own political platform and are on the rise, especially across Europe, raising the question of whether these parties will or should merge in the long term with more traditional green parties. Behavioral economics may also contribute. The attitude of consumers and citizens toward animals, and in particular moral dissonance, anthropocentrism, habits, and social norms certainly play a key role. Finally, the study of preference transmission seems central. Parents and teachers shape the attitudes and perceptions of children toward nature and its resident animals. Observing all these recent trends, we may reasonably expect that our descendants as well as future (environmental) economists will more conscientiously value the welfare of animals.

[Type here] 


\section{Appendix}

The bibliometric analyses depicted in Figures $3 \mathrm{~A}$ and $3 \mathrm{~B}$ are based on queries of the Web of Science ${ }^{\mathrm{TM}}$. For Figure $3 \mathrm{~A}$, the query words <animal welfare>, <animal rights>, and <speciesism> were used to search through abstracts, titles and key words of articles published during any year in Microsoft Academic's top 50 economics journals, ranked by their $h$-index for all years. For Figure 4B, the query words <fishing>, <fashion>, and <meat> were also used to conduct the same search. The journals are, in rank order: The American Economic Review, Journal of Finance, Quarterly Journal of Economics, Journal of Financial Economics, Journal of Political Economy, Econometrica, Management Science, National Bureau of Economic Research, The Economic Journal, Research Policy, Review of Financial Studies, Journal of Economic Perspectives, The Review of Economic Studies, The Review of Economics and Statistics, World Development, Journal of Monetary Economics, Journal of Public Economics, Journal of Economic Literature, Journal of Accounting and Economics, Journal of Accounting Research, Journal of Business Ethics, Ecological Economics, Journal of Banking and Finance, Journal of Business Research, Energy Policy, Journal of International Economics, Journal of Development Economics, Journal of Management Studies, Tourism Management, European Economic Review, Journal of Financial and Quantitative Analysis, Journal of Operations Management, American Journal of Agricultural Economics, Journal of Economic Theory, The RAND Journal of Economics, Climatic Change, Entrepreneurship Theory and Practice, The Journal of Business, Annals of Tourism Research, Journal of Labor Economics, International Journal of Production Economics, California Management Review, International Organization, Journal of Money Credit and Banking, Accounting Organizations and Society, Journal of Human Resources, Marketing Science, Public Administration Review, Journal of Environmental Economics and Management, American Journal of Political Science. The top 5 economic Journals mentioned in the text are The American Economic Review, Econometrica, Journal of Political Economy, Quarterly Journal of Economics and Review of Economic Studies.

\section{References}

Ainslie, George, and R.J. Herrnstein. (1981). Preference reversal and delayed reinforcement. Animal Learning \& Behavior, 9(4):476-482.

Akerlof, George and Robert Shiller. (2009). Animal Spirits. Princeton University Press.

American Pet Products Association (APPA) (2018), 'Historical trends 1996 - 2018'.

Armstrong, Susan and Richard Botzler. (2003). Environmental Ethics: Divergence and Convergence. McGraw-Hill Education.

[Type here] 
Ando Amy and Christian Langpap. 2018. The economics of species conservation. Annual Review of Resource Economics 10: 445 - 467.

Aristotle. (350 BC) Politics. Translation by Benjamin Jowett, The Internet Classics Archive. http://classics. mit.edu/Aristotle/politics.1.one.html.

Asmild, Mette and Jens Leth Hougaard. (2007). Economic versus environmental improvement potentials of Danish pig farms. Agricultural Economics, 35(2):171-181.

Baars, Bernard. (2001). There are no known differences in brain mechanisms of consciousness between humans and other mammals. Animal Welfare, 10(1):3140.

Bar on Yinon M., Rob Philips and Ron Milo. (2018). The biomass distribution on earth, Proceedings of the National Academy of Sciences, 115(25):6506 11.

Bartels, Daniel M. (2006). Proportion dominance: The generality and variability of favoring relative savings over absolute savings. Organizational Behavior and Human Decision Processes 100, 76-95.

Bentham, Jeremy. (1780). An Introduction to the Principles of Morals and Legislation. https://www.econlib.org/library/Bentham/bnthPML.html.

Blackorby, Charles and David Donaldson. (1992). Pigs and Guinea pigs: A note on the ethics of animal exploitation. The Economic Journal, 120(4):1345-1369.

Boardman Anthony E., David Greenberg, Aidan Ving and David Weimer. (2011). Cost-Benefit Analysis: Concepts and Practice. Prentice Hall.

Brown, Gardener and Jason Shogren. (1998). Economics of the endangered species Act. The Journal of Economic Perspectives, 12(3):3-20.

Budolfson, Mark and Dean Spears. (2019a). Public policy, consequentialism, the environment, and non-human animals, forthcoming in the Oxford Handbook of Consequentialism, Oxford University Press.

Budolfson, Mark and Dean Spears. (2019b). Optimal climate policy including animal welfare. Working paper, Princeton CFI.

Butler, Ann and Rodney Cotterill. (2006). Mammalian and avian neuroanatomy and the question of consciousness in birds. The Biological Bulletin, 211(2):106-127.

Broom, Donald. (2014). Sentience and Animal Welfare. CABI Publishing.

Cambridge Declaration on Animal Consciousness.

(2012) http://fcmconference.org/img/CambridgeDeclarationOnConsciousness.pdf.

Clarke Matthew, and Yew-Kwang Ng. (2006). Population dynamics and animal welfare: Issues raised by the culling of kangaroos in Puckapunyal. Social Choice and Welfare 27(2):407-22.

Chalmers, David. (1995). Facing up to the problem of consciousness. Journal of consciousness studies, 2(3):200-19.

Common, Michael and Sigrid Stagl. (2005). Ecological Economics: An Introduction. Cambridge University Press.

Costanza, Robert, Herman Daly and Joy Bartholomew. (1991). Goals, agenda and policy recommendations for ecological economics. In Costanza, Robert (ed.)

[Type here] 
Ecological Economics: The Science and Management of Sustainability. Columbia University Press, NY.

Daly, Herman and Joshua Farley. (2004). Ecological Economics: Principles and Applications. Island Press.

Dawkins, Marian S. (2004) Using behavior to assess animal welfare. Animal Welfare, 13, 3-7.

Dawkins, Richard. (2011). Richard Dawkins on vivisection: "But can they suffer?". http://boingboing.net/2011/06/30/richard-dawkins-on-v.html.

DeGrazia, David. (1996). Taking Animals Seriously: Mental Life and Moral Status. Cambridge University Press.

De Juana, Eduardo. (1992). Class AVES, in Handbook of the birds in the world. Lynx Edicions.

De Petrillo, Francesca, Martina Caroli, Emanuele Gori, Antonia Micucci, Serena Gastaldi, Sacha Bourgeois Gironde and Elsa Addessi (2019) Evolutionary origins of money categorization and exchange: An experimental investigation in tufted capuchin monkeys (Sapajus spp.) Animal Cognition, 22:169-86.

Donaldson, Sue and Will Kymlicka. (2013). A defense of animal citizens and sovereigns. Law, Ethics and Philosophy, 1:143-160.

Dorado, Daniel. (2015). Ethical interventions in the wild. An annotated bibliography. Relations: Beyond Anthropocentrism, 3:219-238.

Dunbar R.I.M., and Shultz, Suzanne. (2007). Evolution in the social brain. Science 317(5843):1344-1347.

Edelman, David, Bernard Baars and Anil K. Seth. (2005). Identifying hallmarks of consciousness in non-mammalian species. Consciousness and Cognition, 14(1):169-187.

Espinosa, Romain and Nicolas Treich. (2019). Animal welfare: Antispeciesism, veganism and a "life worth living". Working Paper.

Everett, Jennifer. (2001) Environmental ethics, animal welfarism, and the problem of predation: A Bambi lover's respect for nature, Ethics \& the Environment, 6(1):42-67.

Faria, Catia and Eze Páez. (2015). Animals in need: The problem of wild animal suffering and intervention in nature". Relations: Beyond Anthropocentrism, 3:7-13

Fédération Européenne de l'Industrie des aliments pour Animaux Familiers (FEDIAF) (2017), 'Facts \& Figures 2016'.

Fisher, James and Roger Tory Peterson. (1964). The world of birds: a comprehensive guide to general ornithology. Macdonald.

Food and Agriculture Organization of the United Nations. FAOSTAT database. http://www.fao.org/faostat/en/\#data/QA.

Francione, Gary. (2008). Animals as Persons: Essays on the Abolition of Animal Exploitation. Cambridge University Press.

[Type here] 
Fraser, David, and Amelia MacRae. (2011). Four types of activities that affect animals: Implications for animal welfare science and animal ethics philosophy. Animal Welfare, 20(4):581-590.

Gallup, Gordon G. (1970). Chimpanzees: Self-recognition. Science 167: 8687.

Gardner, Bruce and Gordon Rausser (ed.). (2002). Handbook of Agricultural Economics. Elsevier Science.

Garrido Joseba, Iker Sevilla, Beatriz Beltrán-Beck, Esmeralda Minguijón, Cristina Ballesteros, Ruth Galindo, Mariana Boadella, Konstantin Lyashchenko, Beatriz Romero, Maria Victoria Geijo, Francisco Ruiz-Fons, Alicia Aranaz, Ramón Juste, Joaquín Vicente, José de la Fuente, Christian Gortázar. (2011). Protection against tuberculosis in Eurasian wild boar vaccinated with heat-inactivated mycobacterium bovis. PLoS One, 6(9):e24905.

Gaston, Kevin, Tim Blackburn and Kees Klein Goldewijk. (2003). Habitat conversion and global avian biodiversity loss. Proceedings of the Royal Society B: Biological Sciences, 270(1521):1293-300.

Gaston, Kevin and Tim Blackburn. (1997). How many birds are there? Biodiversity \& Conservation, 6(4):615-625.

Gosseries, Axel and Tim Meijers. (2019). Animal population ethics. Working paper.

Grethe, Harald. (2017): The economics of farm animal welfare. Annual Review of Resource Economics 9: 75-94

Groff, Zach and Yew-Kwang Ng. (2019). Does suffering dominate enjoyment in the animal kingdom? An update to welfare biology. Biology and Philosophy, 34(4):40.

Gruen, Lori. (2017). The moral status of animals. The Stanford Encyclopaedia of Philosophy.

Grandin, Temple, 2006. (1995). Thinking in Pictures. Vintage Press.

Green, Che. (2016). Animal advocacy by numbers.

Hall, Sally, Brett Nixon and Robert Aitken. (2016). Non-surgical sterilisation methods may offer a sustainable solution to feral horse (Equus caballus) overpopulation. Reproduction Fertility and Development, 29(9):1655-1666.

Hardin, Garret. (1968). The tragedy of the commons. Science, 162(3859): 12430-1248.

Harris, Jonathan. (2006). Environmental and Natural Resource Economics: $A$ Contemporary Approach. Houghton Mifflin Company.

Hestermann Nina, Le Yaouanq Yves and Nicolas Treich. (2018). An economic model of the meat paradox. Mimeo.

Holtug, Nils. (2007). Equality for animals. In New Waves in Applied Ethics, edited by Jesper Ryberg, Thomas S. Petersen, and Clark Wolf, 1-24. Basingstoke: Palgrave Macmillan.

Horta, Oscar. (2010). Debunking the idyllic view of natural processes. Population dynamics and suffering in the wild. Telos, 17 (1):73-90.

[Type here] 
Horta, Oscar. (2013). Zoopolis, intervention, and the state of nature. Law, Ethics and Philosophy, 1:113-125.

Horta, Oscar. (2018). Concern for wild animal suffering and environmental ethics: What are the limits of the disagreement? Les Ateliers de l'Éthique / The Ethical Forum, 13: 85-100.

Huang, Ching-Yu and Ping-Chun Lucy Hou. (2004). Density and diversity of litter amphibians in a monsoon forest of Southern Taiwan. Zoological Studies, 43(4):795-802.

IPBES (2019) Summary for policymakers of the global assessment report on biodiversity and ecosystem services of the Intergovernmental Science-Policy Platform on Biodiversity and Ecosystem Services. Advance unedited version: https://www.ipbes.net/system/tdf/spm global unedited advance. $p$ df?file=1\&type=no de\&id=35245

Irigoien, Xabier, Thor Klevjer, Anders Røstad, Udane Martinez, Guillermo Boyra, José Luis Acuña, Antonio Bode, Fidel Echevarria, Juan Ignacio GonzalezGordillo, Santiago Hernandez-Leon, Susana Agusti, Dag Lorents Aksnes, Carlos Duarte and Stein Kaartvedt. (2014). Large mesopelagic fishes biomass and trophic efficiency in the open ocean. Nature Communications, 5:3271.

Ishwar, N.M, Ravi Chellam and Ajith Kumar. (2001). Distribution of forest floor reptiles in the rainforest of Kalakad-Mundanthurai Tiger reserve, South India. Current Science, 80(3):413-418.

Jennings, Simon, Frédéric Mélin, Julia Blanchard, Rodney Forster, Nicholas Dulyand and Rod Wilson. (2008). Global-scale predictions of community and ecosystem properties from simple ecological theory. Proceedings of the Royal Society B: Biological Sciences, 275(1641):1375-1383.

Johansson-Stenman, Olof. (2018). Animal welfare and social decisions: Is it time to take Bentham seriously? Ecological Economics, 145(C):90-103.

Kaartvedt, Stein, Arved Staby and Dag Lorents Aksnes. (2012). Efficient trawl avoidance by mesopelagic fishes causes large underestimation of their biomass. Marine Ecology Progress Series, 456:1-6.

Kagel, John, Raymond Battalio, Leonard Green. (1995) Economic Choice Theory: An Experimental Analysis of Animal Behavior. Press Syndicate of the University of Cambridge.

Kalenscher, Tobias and Van Wingerden, Marijn. (2011) Why we should use animals to study economic decision making - A perspective, Frontiers in Neuroscience, 10.3389/fnins.2011.00082.

Kant, Immanuel, 1963. (1780). Duties toward animals and spirits, in Lectures on Ethics. Translated by Louis Infield, Harper and Row.

Kymlicka Will and Sue Donaldson. 2011. Zoopolis: A Political Theory of Animal Rights. Oxford University Press.

Keynes, John Maynard. (1936). The General Theory of Employment, Interest and Money. Palgrave Macmillan.

[Type here] 
Knutsonn, Simon and Christian Munthe. (2017). A virtue of precaution regarding the moral status of animals with uncertain sentience. Journal of Agricultural and Environmental Ethics, 30(2):213-224.

Kohda, Masanori et al. (2019). If a fish can pass the mark test, what are the implications for consciousness and self-awareness testing in animals? Plos Biology 17(2):e3000021.

Lagerkvist, Carl Johan and Sebastian Hess. (2010). A meta-analysis of consumer willingness to pay for farm animal welfare. European Review of Agricultural Economics 38(1):55-78.

Loomis, John. (2006). Use of contingent values of wildlife and habitat preservation in policy and benefit cost analyses. In Handbook on Contingent Valuation, Chapter 13.

Lusk, Jason. (2011). The market for animal welfare. Agriculture and Human Values, 28(4):561-575.

Lusk, Jason and F. Bailey Norwood. (2011a). Speciesism, altruism and the economics of animal welfare. European Review of Agricultural Economics, 39(2):189-212.

Lusk, Jason and F. Bailey Norwood. (2011b). Animal welfare economics. Applied Economic Perspectives and Policy, 33(4):463-483.

Lusk, Jason, F. Bailey Norwood, and J. Ross Pruitt. (2006) Consumer demand for a ban on subtherapeutic antibiotic use in pork production. American Journal of Agricultural Economics. 88(4):1015-1033.

MacLean, Evan et al. (2014) The evolution of self-control. Proceedings of the National Academy of Sciences 111 (20):E2140-E2148.

MacMillan, Douglas C., Philip, Lorn, Hanley, Nick and Alvarez-Farizo, Begona. 2002. Valuing the non-market benefits of wild goose conservation: a comparison of interview and group-based approaches. Ecological Economics, 43(1): 49-59.

Maloni, Michael and Michael Brown. (2006). Corporate social responsibility in the supply chain: An application in the food industry. Journal of Business Ethics, 68(1):35-52.

Mankiw, Gregory. (2009). Macroeconomics. Worth Publishers.

Mas-Colell, Andreu. (1995). Microeconomic Theory. Oxford University Press.

Mason, Georgia J., Cooper, Jonathan and Clarebrough, Catherine. (2001). Frustrations of fur-farmed mink. Nature 410:35-36.

Matheny, Gaverick and Kai Chan. (2005). Human diets and animal welfare: the illogic of the larder. Journal of Agricultural and Environmental Ethics, 18(6):579594.

McMullen Steven (2016) Animals and the Economy. Palgrave McMillan.

Miralles, Aurélien, Michel Raymond and Lecointre, Guillaume. (2019) Empathy and compassion toward other species decrease with evolutionary divergence time. Scientific Reports 9, 19555.

[Type here] 
Mood, Alison and P. Brooke. (2012). Estimating the number of farmed fish killed in global aquaculture each year.

Mood, Alison and P. Brooke. (2010). Estimating the number of fish caught in global fishing each year.

Mørkbak, Morten Raun, Tove Christensen and Dorte Gyrd-Hansen. (2009). Valuation of food safety in meat - a review of stated preference studies. Acta Agriculturae Scandinavica, Section C - Food Economics, 5(2):63-74.

Napolitano, Fabio, Corrado Pacelli, Antonio Girolami and Ada Braghieri. (2008). Effect of information about animal welfare on consumer willingness to pay for yogurt. Journal of Dairy Science, 91(3):910-917.

$\mathrm{Ng}$ Yew-Kwang. (1995). Towards welfare biology: Evolutionary economics of animal consciousness and suffering. Biology and Philosophy, 10(3):255-85.

Nocella, Giuseppe, Lionel Hubbard and Riccardo Scarpa. (2009). Farm animal welfare, consumer willingness to pay, and trust: Results of a cross-national survey. Applied Economic Perspectives and Policy, 32(2):275-297.

Norwood F. Bayley and Jayson L. Lusk (2011). Compassion by the Pound. Oxford University Press.

Nozick, Robert. (1974). Anarchy, State, and Utopia. Basic Books.

Nussbaum, Martha C. 2006. Frontiers of Justice: Disability, Nationality, Species Membership, Cambridge, Belknap Press.

Olson, Lars. (2006). The economics of terrestrial invasive species: A review of the literature. Agricultural and Resource Economics Review. 35(1):178-194.

Plato. (360 BC). The Republic. Translation by Benjamin Jowett, The Internet Classics Archive. http://classics.mit.edu/Plato/republic.html.

Perman, Roger, Yue Ma, James McGilvray and Michael Common. (2003). Natural Resource and Environmental Economics. Pearson Education Limited.

Proctor, Helen. (2012). Animal sentience: Where are we and where are we heading? Animals, 2(4):628-639.

Raegan, Douglas and Robert Waide. (1996). The Food Web of a Tropical Rain Forest. University of Chicago Press.

Rawls, John. (1971). A Theory of Justice. Harvard University Press.

Regan, Tom. (1983). The Case for Animal Rights. University of California Press.

Rogers Lesly J. and Gisela Kaplan. (2004). All animals are not equal. The interface between scientific knowledge and legislation for animal rights. In Cass R. Sunstein and Martha C. Nussbaum (ed) Animal Rights: Current Debates and New Directions. Oxford University Press.

Rosati, Alexandra G. (2017). Foraging cognition: Reviving the ecological intelligence hypothesis, Trends in Cognitive Sciences 9: 691-702.

Rousseau, Jean-Jacques. (1755). Discours sur l'Origine et les Fondements de l'Inégalité parmi les Hommes.

Rowlands, Mark (2009 [1998]) Animal Rights: Moral Theory and Practice, Basingstoke: Palgrave Macmillan.

[Type here] 
Rust, Joshua and Eric Schwitzgebel. (2014). The Behavior of Ethicists. Blackwell Companion to Experimental Philosophy.

Santos, Laurie R., and Alexandra G. Rosati (2015). The evolutionary roots of human decision making. Annual Review of Psychology, 66, 321-347.

Schönegger, Philipp and Wagner, Johannes. (2019). The moral behavior of ethics professors: A replication-extension in German-speaking countries. Philosophical Psychology 32 (4):532-559.

Seth, Anil. (2016). Why fish pain cannot and should not be ruled out. Animal Sentience, 3(4).

Singer, Peter. (1975). Animal Liberation. Avon Books, New York.

Singer, Peter. (1980). Utilitarianism and vegetarianism. Philosophy and Public Affairs, 9, 325-37.

Sorby-Adams, Annabel, Robert Vink and Renee Turner. (2018). Large animal models of stroke and traumatic brain injury as translational tools. American Journal of Physiology- Regulatory, Integrative and Comparative Physiology, 315(2):R165R190.

Taiz, Lincoln, Daniel Alkon, Andreas Draguhn, Angus Murphy, Michael Blatt, Chris Hawes, Gerhard Thiel and David G. Robinson. (2019). Plants neither possess nor require consciousness. Trends in Plant Science. https://doi.org/10.1016/j.tplants.2019.05.008

Taylor, Katy, Nicky Gordon, Gill Langley and Wendy Higgins. (2008). ATLA Alternatives to Laboratory Animals, 36(3):327.

Tomasik, Brian. (2009). How many wild animals are there?

Vasudevan, Karthikeyan, Ajith Kumar and Ravi Chellam. (2001). Structure and composition of rainforest floor amphibian communities in Kalakad- Mundanthurai Tiger Reserve. Current Science, 80(3):406-412.

Vasudevan, Karthikeyan, Ajith Kumar, Barry R. Noon and Ravi Chellam. (2008). Density and diversity of the forest floor anurans in the rain forests of Southern Western Ghats, India. Herpetologica, 64(2):207-215.

Veresolgu, Stavros, John Halley and Matthias Rillig. (2015). Extinction risk of soil biota. Nature Communications, 6:8862.

Voltaire. (1764). The Philosophical Dictionary. Translated by H.I. Woolf, Hanover College Department of History. https://history.hanover.edu/texts/voltaire/volanima.html.

Weaber, Robert and Jayson Lusk. (2010). The economic value of improvements in meat tenderness by genetic marker selection. American Journal of Agricultural Economics, 92(5):1456-1471.

Williams, C.B. The range and pattern of insect abundance. (1960). The American Naturalist, 94(875):137-151.

Wilson, Rod, Frank Millero, Josi Taylor, Patrick Walsh, Villy Christensen, Simon Jennings and Martin Grosell. (2009). Contribution of fish to the marine inorganic carbon cycle. Science, 323(5912):359-62.

Witwicki, Kelly. (2019). Global farmed and factory farmed animals estimates.

[Type here] 